\title{
Unfinished but not yet exhausted: A review of Australian Middle Schooling
}

\begin{abstract}
The state of Middle Schooling in many Western countries has been described as under threat, at a crossroads and like a wasteland. Within Australia, it has also been claimed that the past generation focus on Middle Schooling is unfinished and exhausted. But a Middle Schooling movement continues in Australia that provides examples of a way out of a state of arrested development. This article explores the Australian situation in the light of past literature and research, before detailing the potential contributions of a current Australian Research Council project in the area of Middle Schooling. The article argues that, while Middle Schooling may be down in many nations, it is far from down and out, and an Australian perspective has much to offer the Middle Schooling movement internationally.
\end{abstract}

\section{Introduction}

Middle Schooling is at a 'cross roads' in the USA (Anafara, 2001), while a range of tensions place it in a difficult position in many Western nations (Carrington, 2006). Various authors have described Middle Schooling to be a 'wasteland' (Beane, 2001; Silberman, 1970; Smyth \& McInerney, 2007), while others describe a state of 'arrested development' in Middle Schooling reform (Dickinson, 2001, p. xi). In Australia, it has likewise been asserted that the adoption of Middle Schooling has been limited (Hill \& Russell, 1999), with the Middle Schooling project both unfinished and exhausted (Luke et al., 2003). This article details the historical influences that formed and informed the development of the Redesigning Pedagogies in the North (RPiN) project, which seeks to contribute to a new generation of Middle Schooling in Australia.

For the purposes of this article, 'middle years' refers to the ages 10 to 15 (Chadbourne, 2001; Cumming, 1993; Lee Manning \& Bucher, 2005), while 'middle school' refers to a separate organisational structure within or outside of a broader campus (Chadbourne, 2001; George et al., 1992; Lee Manning \& Bucher, 2005). The focus of the article is 'Middle Schooling' (Carrington, 2006; Luke et al., 2003), which is a philosophy of teaching that can be applied in elementary, secondary or specific middle-school contexts. Middle Schooling is often linked to calls for broader school reform so that the application of the philosophy can be 
made more sustainable (Chadbourne, 2001; Smyth et al., 2003) and it is the potential for such reform that is the backdrop to this article.

\section{A brief history of Middle Schooling}

\section{The origins of Middle Schooling}

The origins of Middle Schooling can be found in a difficult coming together of interests around reform for Junior High Schools in the United States approximately 100 years ago. It is beyond the scope of an article that focuses on recent developments in Australian Middle Schooling to explore the contesting complexities that Cuban (1992) highlights around the emergence of American junior high schools. At its simplest, two renditions of the history of Middle Schooling have emerged in the USA. The first, from the Turning points group (Carnegie Council, 1989; Jackson \& Davis, 2000), focuses on the growth of Middle Schooling as a means to support early adolescent developmental needs and provide specific teacher education. The second, led by Beane (2001;2005), provides an explanation that places the student at the centre of an integrated process of meaning making, while remaining sensitive to social, economic and demographic influences. For the sake of brevity, I will rely heavily on the historical account of Beane due to its similar orientation to the Australian Middle Schooling projects that are considered in the latter part of this article.

It was not until the early 1900 s in the USA that the precursors to middle schools-junior secondary schools-were formed. These schools emerged in response to concerns that reached back to the 1870 s about adequately preparing students for college (George et al., 1992) and low student retention (Anafara, 2001; Cuban, 1992). Between 1909 and 1913, the first junior secondary schools opened (George et al., 1992; Lee Manning \& Bucher, 2005) demonstrating the growing influence of psychology on education through an interest in the developmental needs of early adolescents (Anafara, 2001; Cuban, 1992; George et al., 1992). But when junior secondary schools were approved across the USA in 1918 (Lee Manning \& Bucher, 2005), the recognition of student developmental needs within junior secondary schools was still more rhetoric than reality (Beane, 2001).

During the 1930s and 1940s, the issue of student needs within junior secondary schools received renewed interest; this was quelled by the domination of university intellectuals over school curriculum and the impact of McCarthyism on US culture (Beane, 2001). With significant post-war immigration to the USA and a burgeoning baby boom during the 1950s, pressure was again placed on schooling arrangements (George et al., 1992), which elicited pragmatic rather than pedagogic responses (Beane, 2001). By the early 1960s it was widely acknowledged that the junior secondary school movement had increasingly 'imitated what had existed in the past' (Anafara, 2001,p. ix) and had grown to match the title of junior 'high' school (Cuban, 1992).

\section{The emergence of US Middle Schooling}

By the mid-1970s, a distinct middle school reform movement was beginning to take shape (Anafara, 2001; George et al., 1992) and by the end of the 1970s, there 
were more than 10000 middle schools in the USA (Daniels et al., 2001). Behind this growth were more liberal values toward education and racial integration (Beane, 2005; Cuban, 1992; George et al., 1992), the growth in unemployment of early school leavers-due to improvements in technology within lower skilled work (Brown, 2005)-and community and demographic pressures brought about by the baby boom (Beane, 2001; 2005). Throughout the 1980s, a number of state initiatives further established middle schools before the newly formed National Middle Schools Association commenced advocacy for Middle Schooling, including calls for more academic challenge, specific middle-school teacher education and teaching that catered for the developmental needs of early adolescents. With this shift to middle schools and an associated call for more interdisciplinary and integrated curriculum (Beane, 1991; 1995; 1996), a heated debate erupted between progressive and traditional approaches. This resulted in a flurry of research papers culminating in the publication of the influential Turning points report in the late 1980s (Carnegie Council, 1989; Powell et al., 2001). This report identified a mismatch between student needs and school structures or curriculum, as well as high levels of student alienation, significant absenteeism and poor-quality teaching. The Turning points initiative continues to shape the content of most middle-school teacher education and other initiatives in the USA. At the core of Turning points is the promotion of small and connected community schools, a strong academic focus, the pursuit of success for all students, expert middle-school teaching education and the promotion of health and fitness amongst students (Carnegie Council, 1989; Jackson \& Davis, 2000).

By the turn of the millennium, most critics agreed that much of the promise of Middle Schooling had not been fulfilled. While Beane (2001) located much of his criticism in economic rather than educational interests driving change, the Turning points project (Jackson \& Davis, 2000) argued that passive learning, incoherent curriculum, low academic standards and little recognition of diversity had come to typify Middle Schooling. Spurred on by this, the Carnegie Council released a second Turning points report (Jackson \& Davis, 2000) that called for more intellectual demand, 'backward curriculum' design (which starts with learning outcomes and plans backward to content and classroom activity), and greater standardisation. Yet, for some, this approach risked US Middle Schooling losing its identity as it was besieged by both neo-liberals and neo-conservatives through high-stakes testing and aspects of the No Child Left Behind initiative (Beane, 2001; Yecke, 2005). How US Middle Schooling advocates respond to these challenges will be crucial to the survival of a movement at a 'cross roads' (Anafara, 2001).

\section{The emergence of Middle Schooling in Australia}

The South Australian based RPiN project draws on a strong heritage of debate around middle-years education in Australia. Throughout the 1970 s and into the 1980s, Australian educators were part of a concerted effort in many Western countries to develop better schooling responses to tackle student disengagement, school failure and alienation (Hill \& Russell, 1999). With South Australia at the fore of new initiatives (Barratt, 1998; Cumming \& Cormack, 1996), Australian Middle 
Schooling adopted from the USA an emphasis on student-centred pedagogies and supporting early adolescent needs as the basis of middle-years education (Hargreaves \& Earl, 1990). Around this time, the In the middle report (Schools Council, 1993) emphasised separate middle schools to support students as they faced the risks of early adolescence, while other reports highlighted the challenges emerging from various forms of social and academic transition (Earl, 1999; Hargreaves et al., 1996). These papers were instrumental to the foundation of the Middle Schooling movement in Australia.

A number of longitudinal research projects were commissioned by the Australian Curriculum Studies Association throughout the 1990 s with a view to using Middle Schooling as a site for socially just educational reform (Brennan \& Sachs, 1998; Pendergast \& Bahr, 2005). Some projects looked at the importance of engagement to avoid student alienation (Cumming \& Cormack, 1996) and argued for greater pastoral care, consultation and genuine decision-making opportunities for middle-year students. These approaches were associated with holistic middleschool reform, more flexible school structures and greater team-teaching (Cumming, 1993).

During the 1990s, two initiatives furthered the Middle Schooling movement. Firstly, the Australian National Schools Network (NSN) emerged to improve learning outcomes through re-examining the traditional practices of teachers by emphasising new understandings of student needs in changing socio-economic circumstances and youth cultures (Ladwig \& White, 1996). It did this with a view to developing more motivated, engaged and academically successful middle-school students (Barratt, 1998). A shift within policy toward greater marketisation of education in the 1990s (Smyth et al., 2000; Thomson, 2002) was accompanied with decisions to reduce support to the NSN, as well as the other major initiative that supported the development of Middle Schooling in Australia, the Disadvantaged Schools Program (DSP) (Connell, 1998; Lingard, 1998). While this seriously curtailed the expansion of social justice approaches, it did not stop the growth of an Australian version of Middle Schooling philosophy that emphasised meeting student needs, working for social equity, supporting transition and improving retention through quality of teaching (Groundwater-Smith et al., 2007; Hattam et al., 2005 ). Both of these initiatives have informed the initial conceptualisation of the RPiN project through an emphasis on student engagement and retention in the context of rapidly changing cultural and economic environments.

The rationale overwhelmingly used by past Middle Schooling advocates in Australia (Barratt, 1998; Braggett, 1997; Cumming, 1993; Eyers et al., 1993) was that early adolescents have specific developmental characteristics that need specialised support. The positive side of this view can be a Middle Schooling interest in student engagement, negotiated curriculum, integrated learning and authentic assessment. The negative side can be a popular construction or 'deficit view' (Carrington, 2006; Hattam et al., 2005) of early adolescence as a time of hormone-driven behaviour, incompetence, hazard, liability and risk, an image that evokes fear and requires control. 'Adolescence' is a socio-historical and cultural construction (Beane, 2005) and as Brown (2005) notes, the conception of 
'adolescent' is built around the 'normal' white middle-class boy and can perpetuate existing social and economic orders (where divergence from this norm is viewed as a problem to be controlled). There is a danger that the widespread application of this construction can mask inadequate responses by school institutions (McInerney \& Smyth, 2004; Slee, 1994), relabel diversity as a biologically driven deficit (Carrington, 2006; Prosser, 2006) and ignore the structural barriers to early adolescents from disadvantaged communities making middle-class choices (Cormack, 1998). The criticism that is levelled at early adolescence is that it can result in limiting the 'liberatory possibilities in middle school education' (Saltman, 2005, p. 19), while the emphasis on 'adolescents' as problems contributes to a growing emphasis on behaviour management practices. As Cormack $(1996 ; 1998)$ warns, there is a danger that an overemphasis on popular constructions of 'early adolescence' can result in a justification of fewer resources for curriculum and pedagogy, as well as a stripping away of many of the principles of Middle Schooling philosophy through more surveillance, back-to-basics teaching and an emphasis on counselling or pastoral care. Further, Carrington (2006) provides a powerful deconstruction of the place of 'early adolescence' in previous Middle Schooling philosophy to highlight a lack of pedagogical innovation in what has come before. The influence of such critique was significant in the initial conceptualisation of the RPiN project through its emphasis on redesigning pedagogy and researching innovation.

\section{Middle Schooling in Australia: unfinished and exhausted?}

Research into past versions of Middle Schooling in Australia seems to support the proposition that reform has not gone far enough. If we look at a middle-school reform model based on the advances of the NSN (Harradine, 1996; Ladwig \& White, 1996; Smyth et al., 2003), we can see that there has been a lot of effort put into structural changes in schools (Hattam et al., 2005) and there has also been some re-culturing work. But the pedagogical change required if Middle Schooling is actually to improve student learning has been underwhelming (Hattam, 2004; Luke et al., 2003).

The Beyond the middle report (Luke et al., 2003) is the most significant review of Middle Schooling in Australia to date and provides the most recent snapshot of the state of Australian Middle Schooling. The Commonwealth Department of Education, Science and Training commissioned the report to explore the progress of Middle Schooling, the quality of teaching and learning, and literacy and numeracy outcomes. The report finds that the past generation of Middle Schooling is unfinished: it has not secured systemic approaches or high intellectual demand. It also finds that the movement is exhausted: it is over a decade old and has not kept apace with the rapid changes in students' lives and contexts. The report finds that Middle Schooling implementation in Australia is patchy and, most significantly, the report notes that the focus on integrated curriculum and authentic assessment in the past has not been matched with a corresponding interest in pedagogy. As a result, the report highlights the Productive Pedagogies project (Hayes et al., 2006; Lingard et al., 2001) that extensively researched the pedagogies of teachers in Australian middle schools. 
Productive Pedagogies enquired into the pedagogical practices of teachers in Year 6, 8 and 11 classrooms in Queensland. It involved developing an observational manual from existing literature, observing pedagogy, refining key elements of the manual and backward mapping of classroom practices to school structures. In doing so, it finds that committed middle-year teachers are using pedagogies to indifferent effect in relation to the multiple differences in contemporary society (Lingard, 2007). This project sees a need for more specific middle-years education of pre-service teachers, as well as development of new pedagogies that make a difference through rigorous and engaging curriculum that is sensitive to the diversity of students' lives (Hayes et al., 2006; Lingard, 2007). It expresses concerns about disengaged middle-year students, a misalignment between curriculum, assessment and pedagogy and organisational structures that do not support student learning. While Beyond the middle (Luke et al., 2003) reports a slightly more positive situation, it concurs that there is a need to consider greater cultural diversity, the impact of information communication technologies, and changing social contexts on student experiences of Middle Schooling. The agreement between these studies-that a new generation of Middle Schooling is needed in Australia to provide more engaging, connected and intellectually demanding pedagogy-is again basic to the initial conceptualisation of the RPiN project.

\section{Challenges for Australian Middle Schooling Unfinished challenges}

A new wave of Middle Schooling in Australia need not dismiss completely what came before. Clearly, that Luke and colleagues (2003) find Middle Schooling to be unfinished suggests that the insights and initiatives of the NSN and DSP that supported Middle Schooling have not lost their relevance, even if new contexts need to be considered.

One insight from the NSN is that linking teachers' professional development with a systematic research program that focuses on school reform is effective (Ladwig \& White, 1996). The NSN is one of the longest lasting examples of teacher-centred reform internationally and still powerfully informs the practice of many principals, school leaders and teachers. The NSN was successful in engaging students and securing improved academic outcomes; another insight from the NSN is that a commitment to connected pedagogy and integrated curriculum that flows to authentic assessment can create relevant life learning and deep student understandings of self, community and the world. In this way, the work of Boomer and colleagues (1992) is still relevant today. While the NSN secured some success in student learning outcomes (Brennan \& Sachs, 1998), a failure by schools to implement the NSN reform model (Hattam, 2005; Ladwig \& White, 1996; Smyth et al., 2000) restricted the extent of this success as did the imposition of key learning areas and standardisation within disciplines-which undermined integrated learning (Brennan \& Sachs, 1998). These challenges must be responded to by a new generation of Middle Schooling in Australia.

The success of the DSP in tackling disadvantage and promoting social equity as a whole-school issue - rather than a matter of individual deficit (Lingard, 
1998) - points to another unfinished challenge for Middle Schooling. Within the DSP, there was evidence that, once teachers were given space to be intellectual about their practice, the innovative and negotiated pedagogy that resulted helped disadvantaged students, while less emphasis on formal teaching and the competitive academic curriculum enabled teachers to harness student diversity (Connell, 1993). This reveals that pedagogy can still seek to resist inequality and unsettle deficit views (Hattam et al., 2005) through positive discrimination (Lingard, 1998). This insight was influential on the conceptualisation of the RPiN project as it adopted a model of positive discrimination that was committed to teaching students overtly about what it takes to do well in schools (Bourdieu, 1984). This positive discrimination was sought through both being explicit about quality criteria for success (Lingard et al., 2001) and valuing students' experiences from outside school within the curriculum (Thomson, 2002). As the gap between rich and poor in Australia continues to grow (McInerney \& Smyth, 2004), such an approach is no less relevant today than it was a decade ago (Lingard et al., 2000).

\section{New challenges}

While these insights from the past still have currency, there are also new contexts and challenges facing Middle Schooling. After the social, economic and political changes of the 1990s, it is time to look again at Middle Schooling (McInerney \& Smyth, 2004). Change is occurring swiftly in Western society with home, family, work and economic contexts far less stable and futures less secure (Castells, 2000; Pocock, 2003; Pusey 2003). Mobility, dislocation, diversity and 'terror' form a much greater part of young people's lives (Carrington, 2006). In addition to this, changes in technology and communications, as well as the growth in media and consumer culture (Schor, 2004), are changing the way that early adolescents think and act with implications for how educators respond (Knobel \& Lankshear, 2003; Prensky, 2001). These changes are producing a previously unseen generational gap between students and teachers (Hayes et al., 2006). Members of a new generation of Middle Schooling must be aware of their own generational baggage, so that the opportunities for early adolescents and Middle Schooling will not be limited by an inability to imagine and to respond to life in the new knowledge economy (Carrington, 2006). A new generation of Middle Schooling needs to respond to 'deficit' constructions of early adolescence that pre-date 'the move to a society characterised by discourses of risk and risk taking' by calling for a reduction in the dependence on 'developmental psychology views' because they have not resulted in better learning outcomes (Carrington, 2006, p. 51).

A new generation of Australian Middle Schooling must also respond to past criticisms by fostering academic and intellectual rigour (Luke et al., 2003). It will include relevance, negotiation, integration and authentic achievement as well as an appreciation of the growing diversity among students (Carrington, 2006; Lingard et al., 2001) and be aware of changing social and technological contexts (Carrington, 2006; Luke et al., 2003). The challenge facing Middle Schooling is to take the opportunity for greater engagement with the wider world through more recognition of student lives, more productive approaches to notions of risk or self, 
and 'glocal' (Carrington, 2006, p. 169) approaches to local and global issues. This engagement needs to embrace new pedagogies and literacies, as well as devise learning environments and experiences that cater for the highly individualistic, reflexive and agentive nature of our emerging citizens. Pleasingly, such an emphasis on student diversity, identity, agency and reflection is beginning to appear in contemporary Australian Middle Schooling research projects such as RPiN.

\section{Continuing challenges}

As research fellow to the RPiN project, and now as a Middle School teacher educator, I am continually confronted by a challenge. This challenge is the gap between a Middle Schooling philosophy that is developed and advocated within universities and the everyday realities of schools. When my students return from their practicum placements in middle-year settings, some bemoan the irrelevance of university 'theory', some tell of their despair when faced with the situation in schools while others recount their efforts to enact Middle Schooling philosophy in unsupportive environments. Further, when speaking with teaching colleagues working in schools, I often find derision toward the phrase 'Middle Schooling' as it is associated with an initiative of two decades ago that failed to reach its potential. In this context, the reflections of Beane seem relevant:

$[T]$ he middle school concept as it was really meant to be is found on a wholeschool basis in relatively few places. To see it in action one doesn't visit schools per se; rather, one tries to find particular individuals or teams who are managing to keep the concept alive inside a school, often under attack from colleagues and public critics. (2001, p. xx)

If this is the experience of Middle Schooling for most teachers, why would they have interest or energy for new Middle Schooling philosophy? I argue that advocates of Middle Schooling need to turn their attention to the chasm between developing philosophy and existing classroom practices if a new generation is not to go the way of its predecessor.

When we look at the renewed emphasis on Middle Schooling in recent years, there is evidence of researchers and teacher educators embracing this challenge. Since 2005 this interest in Middle Schooling has resulted in a flood of new publications. While some provide in-service and pre-service teachers with insights into policy contexts, early adolescent changes and classroom approaches (Knipe, 2007; Pendergast \& Bahr, 2005), others provide case studies of socially just Middle Schooling success for teachers (Groundwater-Smith et al., 2007; Smyth \& McInerney, 2007). Still others reflect on the future of the movement in a digital age (Carrington, 2006; Knipe, 2007). But when one of the most significant criticisms of the Middle Schooling movement is that it is being driven by advocacy rather than research (Chadbourne, 2001; Earl, 1999; Hill \& Russell, 1999), none of these texts explicitly considers the important area of school-based teacher pedagogical inquiry (Reid, 2004). There is a need for a stronger teacher research base to a new generation of Middle Schooling (Cumming \& Cormack, 1996; Hunter, 2007; Luke et al., 2003; Main \& Bryer, 2007; Pendergast \& Bahr, 2005) and it is this need for research that was another important factor in the planning and development of the RPiN project. 


\section{The Redesigning Pedagogies in the North project}

By way of background, the Redesigning Pedagogies in the North project is an Australian Research Council Linkage project working with 10 middle or secondary schools within Adelaide's northern urban fringe. This region experiences high levels of poverty, early school leaving and youth unemployment, and a reduction in traditional career pathways (Elliott et al., 2005; Peel, 1995). By choosing to form a partnership with schools in some of the most socially disadvantaged suburbs in Australia, the RPiN project took up the continuing challenge of differential schooling outcomes due to socio-economic disadvantage. The theoretical underpinning of this approach drew on a model of pedagogical development that incorporates the 'funds of knowledge' (Moll et al., 1992) from student lives as well as teaching the codes of 'cultural capital' (Bourdieu, 1984) in the mainstream curriculum. The project argues that young people from diverse social positions enter schooling with differing qualities and degrees of 'cultural capital' and that, increasingly, the gap between students' lives and standardised schooling is resulting in this diversity being deemed a problem. In response, 'funds of knowledge' provide a mirror to 'cultural capital' through an understanding of how families generate, obtain and distribute knowledge; this understanding is then used as a resource for making community and household assets 'pedagogically viable' (Gonzales \& Moll, 2002, p. 278). Thomson (2002) extends these ideas in her consideration of schooling in Adelaide's northern urban fringe through the metaphor of the 'virtual schoolbag'. This 'schoolbag' of 'funds of knowledge' that all students bring to school (only some of which count as 'cultural capital' in the school setting) can be used as a resource to help teachers identify stronger connections between students' lives and curricular learning. It is the attempt by teachers to engage in pedagogical innovation and to conduct research into these attempts that is the basis of the RPiN method. To support this research, the RPiN university team created a community of enquiry with the teacher researchers to provide the intellectual space to assist them in their efforts to redesign pedagogy and realise reform. The RPiN project commenced in 2005 and is scheduled for completion at the end of 2008 .

\section{Principles for bridging philosophy and realities}

When faced with a chasm between Middle Schooling philosophy and everyday school life, it is important to provide tangible examples of new pedagogies and explore what they might look like in schools. The RPiN project seeks to contribute to a new generation of Middle Schooling by making teachers central to the process. It has adopted a particular approach to its education research: namely, partnerships with teachers to produce critical action research about their pedagogy in the middle years. This form of research, as demonstrated by Comber and Kamler (2005), supports teachers to reclaim their work by producing knowledge and enhancing their expertise over their practice. This professional-practice centred approach differs from other recent Australian Middle Schooling research in that it starts with teachers' views and experiences of pedagogy, rather than using literature to derive observations of classroom practices. Thus the RPiN approach contributes to the growing body of research not only tangible attempts to enact new Middle 
Schooling philosophy but also insights into the constraints and complexities experienced by teachers in their school contexts.

One example from RPiN project involved two teacher researchers' efforts to put more emphasis on the 'home' in homework with their Year 8 classes (Quinn et al., 2008). Their pedagogical move was to place greater value on the 'funds of knowledge' of students in the school context by expanding Lillico's (2004) Homework Grid to emphasise the learning and expertise that students use with their families. The sorts of activities that students chose as homework involved mathematical capabilities through budgeting and shopping for food, design and technology capabilities through problem-solving when working on cars, or teaching capabilities through coaching junior sport. The data that was collected on the homework initiative demonstrated an increase in student engagement as well as evidence of the two teachers using this new knowledge to redesign curriculum within two key learning areas. But, in the case study, a school culture that resisted the relaxing of traditional subject-centred curriculum priorities resulted in a homework grid that made greater demands on teacher time and school organisational structures, both of which inhibited change. The study also identified other practical, structural and cultural complexities that acted as constraints in this school context and continue to present a challenge to the initiative's sustainability. These insights remind us of both the NSN model of reform and the importance of not falling into the trap of thinking that teachers and pedagogy are all that matter in relation to schooling and social justice (Lingard \& Mills, 2007). The 'home'work project is but one of 30 studies within the RPiN project, highlighting the potential for the project to make an ongoing contribution to Middle Schooling research and reform.

Secondly, building school-university bridges not only requires collaboration with teachers in the process but it also requires the provision of practical pedagogical resources to support the development of 'virtual schoolbag' initiatives in classrooms. To help teachers to do this, the RPiN project drew on a range of resources including 'turnaround pedagogies' (Comber \& Kamler, 2005), 'placebased pedagogies' (Smith, 2002) and 'narrative identity' (Hattam \& Prosser, 2008). Each of these resources embodies the principles of new-generation Middle Schooling philosophy and different teachers have found each stimulating and productive.

While examples of the application of these pedagogical resources will be an important future contribution of the RPiN project, another associated contribution is the consideration of how teachers respond to and adopt alternative pedagogical resources. The majority of teachers within the RPiN project completed their teacher education before the completion of the Beyond the middle report in 2003. It was not surprising then, to find that few were informed by recent moves to re-emphasise pedagogy in Middle Schooling philosophy, particularly when most described the growing demands on teachers' work as leaving little time for professional development or reading. Initially, the RPiN project found that teachers were uncomfortable with or unwilling to use 'pedagogy' in talking about their teaching practice. While resistance to the term decreased as it became more familiar during 2005 , the initial round of research reports from the teacher researchers mainly 
focused on drawing resources from students' 'virtual schoolbags' to identify new teaching content and to research if attendance or work completion increased as a sign of student engagement. This outcome saw the RPiN project take a more explicit approach to pedagogy during 2006.

This more explicit approach to pedagogy was attempted through theorisation of the possible cause for difficulties in talking with the teachers explicitly about their pedagogies (Sellar \& Cormack, 2007). For instance, teachers kept returning to the importance of relationships with students as the key to teaching and learning but, as Lingard (2007) observes, supportive relationships by committed teachers do not always result in pedagogies that support intellectual demand and value diversity. The university team was faced with the challenge of determining how they could listen to what the teachers had to say, while still relating this to a new generation of Middle Schooling philosophy in its emphasis on pedagogy. It became apparent that a shared conception of pedagogy was important if the project was going to redesign pedagogical practice.

One possible explanation for the initial difficulty around the word 'pedagogy' was that historically the South Australian Department of Education and Children's Services had used terms such as 'teaching and learning' rather than 'pedagogy' (Sellar \& Cormack, 2007, p. 2). But, over time, it became clear that it was more complex than conceptual slippage and that 'there wasn't a shared language for talking about pedagogy between and among the teachers and researchers' (Sellar \& Cormack, 2007, p. 2). In response, a 'heuristic framework' was developed to support dialogue between teacher and university researchers (Sellar \& Cormack, 2007, p. 6). Drawing on the work of Lusted (1986), Boomer and colleagues (1992) and Hayes and colleagues (2006), a 'recursive pedagogical processes' model (Sellar \& Cormack, 2007) was produced to emphasise the range of practices that teacher researchers reported using in their classroom, such as researching, designing, communicating, transforming, performing and reflecting.

From the resulting discussion around this model, several teachers identified that they were 'light on' in regard to pedagogical 'reflection' (Sellar \& Cormack, 2007 , p. 12). This realisation formed the basis of their research projects in 2006. Subsequent analysis of group discussions with teachers by the university team also found that other pedagogical practices were less evident in teacher talk about their pedagogy (Sellar \& Cormack, 2007, p. 14). Notably, teachers were comfortable discussing researching, designing and communicating, but when it came to transforming, performing and reflecting, 'teachers' talk about pedagogy rapidly diminished into silence' (Sellar \& Cormack, 2007, p. 14). It is here that RPiN makes an important contribution. While other heuristics like 'productive pedagogies' (Lingard et al., 2001) focus on the outcomes of teaching and learning such as 'deep understanding', what this RPiN heuristic contributes is additional information around the day-to-day practices that might lead to such outcomes, as well as providing a tool that can be adapted by other research projects. In the case of the RPiN project, the use of this heuristic resulted in more teacher researchers developing a focus on how their pedagogical practices in the classroom had an impact on learning in the second research cycle of the project. (While this article provides 
Table 1 The range of practices teacher researchers used in classrooms

\begin{tabular}{|c|c|c|c|c|c|}
\hline Researching & Designing & $\begin{array}{l}\text { Communi- } \\
\text { cating }\end{array}$ & Transforming & Performing & Reflecting \\
\hline $\begin{array}{l}\text { Students and } \\
\text { teachers } \\
\text { research } \\
\text { community and } \\
\text { personal funds } \\
\text { of knowledge } \\
\text { in order to } \\
\text { negotiate rich } \\
\text { and connected } \\
\text { curriculum } \\
\text { tasks }\end{array}$ & $\begin{array}{l}\text { Students and } \\
\text { teachers } \\
\text { negotiate and } \\
\text { collaborate to } \\
\text { design learning } \\
\text { activities, } \\
\text { assessment } \\
\text { structures and } \\
\text { classroom } \\
\text { operation }\end{array}$ & $\begin{array}{l}\text { Students and } \\
\text { teachers } \\
\text { communicate } \\
\text { through a } \\
\text { variety of } \\
\text { modes to share } \\
\text { understandings } \\
\text { and offer } \\
\text { explicit } \\
\text { instruction }\end{array}$ & $\begin{array}{l}\text { Students } \\
\text { actively } \\
\text { interact with } \\
\text { their worlds } \\
\text { and transform } \\
\text { knowledge } \\
\text { gained through } \\
\text { this interaction } \\
\text { into a variety } \\
\text { of media }\end{array}$ & $\begin{array}{l}\text { Students } \\
\text { perform their } \\
\text { learning and } \\
\text { act upon their } \\
\text { worlds in high } \\
\text { stakes } \\
\text { situations for a } \\
\text { variety of } \\
\text { school and } \\
\text { community } \\
\text { audiences }\end{array}$ & $\begin{array}{l}\text { Students and } \\
\text { teachers reflect } \\
\text { on their } \\
\text { learning, cele- } \\
\text { brating } \\
\text { successes, } \\
\text { 'feeling the } \\
\text { quality' and } \\
\text { identifying } \\
\text { future } \\
\text { challenges }\end{array}$ \\
\hline
\end{tabular}

Source: Sellar \& Cormack, 2007

a general account of the shift of the 30 teachers toward greater use of the term 'pedagogy' and emphasis on their pedagogical practices in their research, for more detailed analysis of teacher discussion see Sellar \& Cormack, 2007; see RPiN, 2008, for individual accounts of each teacher researcher's journey.)

A third contribution that RPiN makes to the ongoing Middle Schooling project is in its examination of the conditions that are needed to surround and sustain reform. By responding to a call for multi-partnered and research-based Middle Schooling initiatives, we are partnering schools to produce examples of successful reform. Currently, the process is working with teachers to document their research, as well as with their principals to disseminate, sustain and develop the findings of this research. While the $\mathrm{RPiN}$ project shares with other projects the assumption (Lingard \& Mills, 2007) that pedagogy is a central issue for social justice, it also responds to a challenge to sustain examples of reform that are driven by professional learning (Johnston \& Hayes, 2007). Thus, this research partnership with schools will continue to contribute new information about the capacity for structural and cultural reform to support pedagogical change in urban fringe communities.

In summary, the early discoveries of the RPiN project point to several contributions to a new generation of Middle Schooling research and practice in Australia. By forging a partnership with schools and collaborating with teacher researchers, $\mathrm{RPiN}$ is dealing with criticisms that past Middle Schooling philosophy has not been grounded in systematic enquiry, while it simultaneously works to reduce the gap between emergent philosophy and classroom practice. Further, by drawing on students' 'funds of knowledge' the project is designing and analysing examples of Middle Schooling pedagogical innovation that deliberately resist the deficit views that surround the growing diversity amongst student cohorts and the persistent challenges of urban-fringe communities. In doing so, the project must also grapple with the challenge of conceptualisation around the new generation of Middle Schooling's emphasis on pedagogy. One response has been to contribute a 
pedagogical heuristic to support teacher and university researchers in dialogue around pedagogical practice. Another has been to start working with teachers and their school communities to identify and to tackle the complexity and constraints that can be barriers to socially just Middle Schooling reform. The results of these efforts will be the subject of subsequent publications and part of an ongoing contribution to the development of Australian Middle Schooling.

\section{Conclusion}

Within Australia, as in many Western countries, Middle Schooling has been described as under threat but there are collaborative university-school projects emerging in Australia that point towards a way out of a state of arrested development. It is vital that such projects (which reduce the gap between a new generation emphasis on pedagogy and everyday classroom practices) are documented, just as it is important that future research examine how tertiary teacher preparation can further reduce this gap. In response, this article has presented a brief historical review of the development of the Middle Schooling concept in the USA and Australia that acts as a foundation for a consideration of the possible contributions of the Redesigning Pedagogies in the North research project to a new generation of Middle Schooling philosophy and practice in Australia.

\section{Key words}

middle schools educational change

middle years

literature reviews educational history university school cooperation

\section{References}

Alexander, W. M., \& Williams, E. (1968). The emergent middle school. New York: Holt, Rinehart \& Winston.

Anafara, V. A. (2001). The handbook of research in middle level education. USA: Information Age Publishing.

Barratt, R. (1998). Shaping Middle Schooling in Australia: $A$ report of the national Middle Schooling Project. Deakin West: Australian Curriculum Studies Association.

Beane, J. A. (1991). The Middle School: Natural home of integrated curriculum. Educational Leadership, 49, 9-13.

Beane, J. A. (1995). Curriculum integrations and the disciplines of knowledge. Phi Delta Kappan, 76, 616-622.

Beane, J. A. (1996). On the shoulders of giants! The case for curriculum integration. Middle School Journal, 28, 6-11.

Beane, J. A. (2001). Introduction. In T. S. Dickinson (Ed.), Reinventing the Middle School, xiii-xxi. New York: Routledge Falmer.

Beane, J.A. (2005). Foreword. In E. R. Brown \& K. J. Saltman (Eds), The Critical Middle School Reader, xi-xv. New York: Routledge.

Boomer, G., Lester, N., Onore, C. \& Cook, J. (Eds) (1992). Negotiating the curriculum: Educating for the 21st century. London: The Falmer Press.

Bourdieu, P. (1984) Distinction: A social critique of the judgement of taste. London: Routledge \& Kegan Paul.

Braggett, E. (1997). The middle years of schooling: An Australian perspective. New South Wales: Hawker Brownlow Education. 
Brennan, M., \& Sachs, J. (1998). Integrated curriculum: Classroom materials or the middle years. Deakin West: Australian Curriculum Studies Association/National Schools Network.

Brown, E. R. (2005). Introduction. In E. R. Brown \& K. J. Saltman (Eds). The critical middle school reader. London \& New York: Routledge, 1-14.

Carnegie Council. (1989). Turning points. Boston, MA: Center for Collaborative Education.

Carrington, V. (2006). Rethinking the middle years: Early adolescents, schooling and digital culture. Sydney: Allen \& Unwin.

Castells, M. (2000). End of millennium. Malden: Blackwell.

Chadbourne, R. (2001). Middle Schooling for the middle years: What might the jury be considering? Melbourne: Australian Education Union.

Connell, R. W. (1998). Social change and curriculum future. Change: Transformations in education, 1, 84-90.

Connell, R. W. (1993). Work for teachers. Schools and social justice, 57-73. Melbourne: Pluto Press.

Comber, B., \& Kamler, B. (2005). Turn-around pedagogies: Literacy interventions for at-risk students. Sydney: Primary English Teaching Association.

Cormack, P. (1996). Constructions of the adolescent in newspapers and policy documents: Implications for Middle Schooling. South Australian Educational Leader, 7, 1-12.

Cormack, P. (1998). Middle Schooling: For which adolescent? Curiculum Perspectives, 18, $56-60$.

Cuban, L. (1992). What happens to reforms that last? The case of the junior high school. American Educational Research Journal, 29(2), 227-251.

Cumming, J. (1993). Middle Schooling for the 21st century. Melbourne: IARTV.

Cumming, J. \& Cormack, P. (1996). From alienation to engagement. Canberra: ACSA.

Daniels, H., Bizar, M., \& Zemelman, S. (2001). Rethinking high school: Best practice in teaching, learning and leadership. Portsmouth, NH: Heinemann.

Dickinson, T. S. (2001). Reinventing the middle school. NY: Routledge Falmer.

Earl, L. M. (1999). Education for the middle years: The paradox of hope. Melbourne: IARTV.

Elliott, M., Sandeman, P., \& Winchester, H. (2005). Embedding community engagement: Northern Adelaide and the University of South Australia. Paper presented at the 4th Australian University Quality Forum, Sydney, 6-8 July.

Eyers, V., Cormack, P. and Barratt, R. (1993). The education of young adolescents in South Australian government schools: Report of the Junior Secondary Review. Adelaide: Education Department of South Australia.

George, P. S., Stevenson, C., Thomason, J., \& Beane, J. (1992). The middle school-and beyond. Virginia USA: Association for Supervision of Curriculum Development.

Gonzalez, N., \& Moll, L. (2002). Cruzando el puente: Building bridges to funds of knowledge. Educational Policy, 16(4), 623-641.

Green, B., \& Bigum, C. (1993). Aliens in the classroom. Australian Journal of Education, 37, $119-141$.

Groundwater-Smith, S., Mitchell, J. \& Mockler, N. (2007). Learning in the middle years: More than a transition. Melbourne: Thomson.

Hargreaves, A. \& Earl, L. (1990). Rights of passage: A review of selected research about schooling in the transition years. Toronto: Ministry of Education, Ontario.

Hargreaves, A., Earl, L. M., \& Ryan, J. (1996). Schooling for change: Reinventing education for early adolescents. London: The Falmer Press. 
Harradine, J. (1996). What research tells us about school reform. National Schools Network Newsletter, 2, 4-5.

Hattam, R. (2005). The (im)possibility of listening to early school leavers: Implications for Middle Schooling. Australian Guidance \& Counselling Association Annual Conference, Adelaide.

Hattam, R. (2004). Connecting classrooms to student lifeworlds: Imagining the teacher-as-ethnographer. Pursuing social justice in education: Working the exquisite tension of our times, AARE Annual Conference, Melbourne.

Hattam, R., Prosser, B., \& Brady, K. (2005). Unsettling deficit views of students and their communities. Australian Association for Research in Education Annual Conference. Parramatta, 28 November.

Hattam, R., \& Prosser, B. (2008). Unsettling deficit views of students and their communities. Australian Educational Researcher, 35(2) (in press).

Hattam, R. \& Smyth, J. (2003). 'Not everyone has a perfect life': Becoming somebody without school. Pedagogy, Culture and Society, 11, 379-398.

Hayes, D., Mills, M., Christie, P., \& Lingard, B. (2006). Teachers and schooling making a difference: Productive pedagogies, assessment and performance. Sydney: Allen \& Unwin.

Hill, P. W., \& Russell, V. J. (1999). Systemic whole school reform of the middle years of schooling. In R. J. Bosker, P. M. Creemers \& S. Stringfield (Eds), Enhancing educational excellence, equity and efficiency, 167-196. Dordrecht: Klewer Academic Publishing.

Hunter, L. (2007). Editional: Machinations in the middle. Australian Educational Researcher, $34(2), 1-5$.

Jackson, A. W. \& Davis, G. A. (2000). Tuming points 2000: Educating adolescents in the 21st century, New York: Teachers' College Press.

Johnston, K. \& Hayes, D. (2007). Supporting student success at school through teacher professional learning: The pedagogy of disrupting the default modes of schooling. International Journal of Inclusive Education, 11(3), 371-381.

Knipe, S. (2007). Middle years schooling. Sydney: Pearson.

Knobel, M., \& Lankshear, C. (2003). Planning pedagogy for i-mode: From flogging to blogging via wi-fi. English in Australia-Literacy Learning: The middle years, 139(Summer), 78-102.

Ladwig, J. G. \& White, V. (1996). Integrating research and development in the National Schools Network. Australian Journal of Education, 40(3), 302-310.

Lee Manning, M. \& Bucher, K. T. (2005). Teaching in the middle school. Upper Saddle River, NJ: Pearson.

Lillico, I. (2004). Homework and the homework grid. Perth: Tranton Enterprises P/L.

Lingard, B. (1998). The disadvantaged schools programme: Caught between literacy and local management of schools. International Journal of Inclusive Education, 2, 1-14.

Lingard, B. (2007). Pedagogies of indifference. International Journal of Inclusive Education, 11(3), 245-266.

Lingard, B., Ladwig, J., Luke, A., Mills, M., Hayes, D., \& Gore, J. (2001). Queensland school reform longitudinal study: Final report. Brisbane: Education Department.

Lingard, B. \& Mills, M. (2007). Pedagogies making a difference: Issues of social justice and inclusion. International Journal of Inclusive Education, 11(3), 233-244.

Lingard, B., Mills, M., \& Hayes, D. (2000). Teachers, school reform and social justice: Challenging research and practice. Australian Educational Researcher, 27, 99-115.

Luke, A., Elkins, J., Weir, K., Land, R., Carrington, V., Sole, S.,Pendergast, D., Kapitzke, C., van Kraagenoord, C., Moni, K., McIntosh, A., Mayer, D., Bahr, N., Hunter, L., 
Chadbourne, R., Bean, T., Alverman, T. \& Stevens, L. (2003). Beyond the middle: $A$ report about literacy and numeracy development of target group students in the middle years of schooling, 1. Canberra: Department of Education, Science and Training.

Lusted, D. (1986). Why pedagogy? Screen, 27(5), 2-14.

McInerney, P., \& Smyth, J. (2004). You have to view the child as a person and not a commodity. AARE Annual Conference, Melbourne.

Main, K. \& Bryer, F. (2007). A framework for research into Australian Middle School practice. Australian Educational Researcher, 34(2), 91-106.

Moll, L., Amanti, C., Neff, D., \& Gonzalez, N. (1992). Funds of knowledge for teaching: Using a qualitative approach to connect homes to classrooms. Theory into Practice, 31(2), 132-141.

Peel, M. (1995). Good times, hard times: The past and the future in Elizabeth. Melbourne: Melbourne University Press.

Pendergast, D., \& Bahr, M. (Eds) (2005). Teaching middle years: Rethinking curriculum, pedagogy and assessment. Sydney: Allen \& Unwin.

Pocock, B. (2003) The Work/Life Collision. Sydney: Federation Press.

Powell, R., et al. (2001). Middle School Curriculum. In V. A. Anafara, The handbook of research in middle level education, 107-124. USA: Information Age Publishing.

Prensky, M. (2001). Digital natives, digital immigrants: a new way to look at ourselves and our kids. On the Horizon, 9(5). Retrieved 10 October, 2007 from http://www. marcpresnsky.com

Prosser, B. (2006). ADHD: Who's failing who? Sydney: Finch.

Pusey, M. (2003) The experience of middle Australia: The dark side of economic reform. Cambridge: Cambridge University Press.

Quinn, R. Prosser, B. \& Hattam, R. (2008). Putting the 'home' back into homework: Implications for middle school reform. Curriculum Perspectives (accepted for publication-November).

Redesigning Pedagogies in the North (2008). Retrieved 24 May, 2008 from http://www. ansn.edu.au/connecting_lives_and_learning

Reid, A. (2004). Toward a culture of inquiry in DECS. Occasional paper series, 1 . Retrieved 10 October, 2007 from http://www.decs.sa.gov.au/corporate/files/links/OP_ 01.pdf

Saltman, K.J. (2005). Social construction of identity. In E. R. Brown \& K. J. Saltman (Eds), The critical middle school reader, 15-20. New York: Routledge.

Sapon-Shevin, M. (2005). Afterword. In E. R. Brown \& K. J. Saltman (Eds), The critical middle school reader, 521-523. New York: Routledge.

Schools Council (1993). In the middle: Schooling for young adolescents. Project paper, 7. Canberra: Schools Council, National Board of Employment, Education and Training.

Schor, J. (2004). Born to buy: The commercialised child in the new consumer culture. New York: Simon \& Schuster.

Sellar, S. \& Cormack, P. (2007). Redesigning pedagogies in the middle years: Challenges for teachers working with disadvantaged students. Redesigning Pedagogy: Culture, Knowledge and Understanding conference, Singapore, 28-30 May.

Silberman, C. (1970). Crisis in the classroom: The remaking of American education. New York: Random House.

Slee, R. (1994). Finding a student voice in school reform: Student disaffection, pathologies of disruption and educational control, International Studies in the Sociology of Education, 4, 147-172. 
Smith, G. (2002) Place-based education: Learning to be where we are. Phi Delta Kappan, $83,584-594$.

Smyth, J., Hattam, R., Cannon, J., Edwards, J., Wilson, N., \& Hurst, S. (2000). Listen to me I'm leaving': Early school leaving in South Australian secondary schools. Adelaide: Flinders Institute for the Study of Teaching.

Smyth, J. \& McInerney, P. (2007). Teachers in the middle: Reclaiming the wasteland of the adolescent years of schooling. New York: Peter Lang.

Smyth, J., McInerney, P., \& Hattam, R. (2003). Tackling school leaving at its source: A case of reform in the middle years of schooling. British Journal of Sociology of Education, 24, 177-193.

Thomson, P. (2002). Schooling the rustbelt kids: Making the difference in changing times. Sydney: Allen \& Unwin.

Yecke, C. (2005). Mayhem in the middle: How middle schools have failed America and how to make them work. Washington, DC: Thomas B. Fordham Institute.

\section{Acknowledgements}

This publication is an outcome of the collaborative Redesigning Pedagogies in the North project, funded by the Australian Research Council (LP0454869), between the Centre for Studies in Literacy, Policy and Learning Cultures (University of South Australia), the Northern Adelaide State Secondary Principals Network (NASSPN), the Australian Education Union (SA Branch) and the South Australian Social Inclusion Unit. The research team includes Associate Professor Robert Hattam, Associate Professor Phillip Cormack; Professor Barbara Comber; Professor Marie Brennan; Dr Lew Zipin; Professor Alan Reid; Dr Kathy Paige; Dr David Lloyd; Associate Professor Helen Nixon; Mr Bill Lucas; Dr Faye McCallum; Ms Philippa Milroy; Mr Sam Sellar.

\section{Author}

Dr Brenton Prosser is Lecturer (Middle Years) at the University of South Australia and a key researcher in the Centre for Studies in Literacy, Policy and Learning Cultures.

Email: Brenton.Prosser@unisa.edu.au 